\title{
An Analysis of Wushu's Theoretical Concept and its Reflection in Wushu's Practice
}

\author{
Xiaomei Lin ${ }^{1}$, Borislava Lecheva ${ }^{2}$ \\ ${ }^{1}$ (Head of Sports Department, Educational College, Zhejiang University, China) \\ ${ }^{2}$ (MA Chinese Traditional Sport, Sports Department, Educational College, Zhejiang University, China)
}

\begin{abstract}
Wushu is an essential part of Chinese culture. It is highly valued for its defensive, health-preserving, entertaining and educational functions. It has a rich history and its development can be traced from the dawn of the Chinese civilization till its present status as a sports discipline aiming to enter the Olympic Games. The internationalization of Wushu being one of the main concerns in the context of its present development suggests the existence of comprehensible literature that can provide the non-Chinese reader with a better understanding of Wushu. Therefore, this paper introduces health-preserving, social-regulating and harmonizing functions of Wushu, the way they are reflected in its practice.
\end{abstract}

Key Words: Wushu, traditional Chinese culture, martial arts

\section{Introduction}

Chinese culture is unique for its understanding about knowledge. Theory cannot be explained without its practical application, the same way that practice has its theoretical basis. This idea is reflected in the language itself, for example the phrase 知行合一, which means that knowledge and actions should go hand in hand. In other words, what one knows should be applied, what one applies should come from his own knowledge. Another word that expresses the same idea is 教训 - teaching a lesson from one's own experience. Wushu does not make any exception of this understanding. That is why it is very difficult to be discussed without any practical experience. 'The very cream and true essence of Wushu can be learned only through thought and actual body movements' [1]. From a Chinese phenomenon, Wushu has become a world sensation. Fascinated by the beauty of its motions and the philosophy behind them, people from all around the world are drawn to its birth place - China - in order to improve their practical skills and deepen their understanding of Wushu's culture. Nowadays, the technical progress makes it easy for us to find information about what we are interested in. However, despite all the sources concerning Wushu there are still some misunderstandings about its concept and theoretical basis. By introducing three aspects of Wushu's theory and the way they are reflected in Wushu's practice, this paper highlights 1) Wushu's health preserving and health improving functions; 2) Wushu's importance as a system regulating social interactions; 3) Wushu as a way to achieve harmony.

\section{What is $Q i$}

\section{The Concept of Qi in Wushu's Theory and Practice}

There is a concept in Wushu's theory reflected in its practice as well which gives rise to a great deal of curiosity among people but at the same time is often misinterpreted, and as a consequence has contributed to the mysterious image some Asian practices have gained. The matter in hand is Qi, whose concept is also present in other Asian cultures such as the Indian understanding about Prana in Yoga and the one about Ki in the Japanese martial arts. Qi, Ki or Prana can all mean vital energy or life force. According to the ancient beliefs it is considered to be 'the source of the constitution of the world and the material basis of vital activities' [2]. Other possible ways for Qi to be described are 'bioelectric life force, psychophysical energy or psychobiological force' [3]. From physiological point of view Qi refers to the breathing process which is strongly connected with all the functions of the human body. Cellular metabolism is the energy producing process within the cell for which the oxygen delivered to the body by breathing is responsible [4]. This process is unconscious and continuous but through practice a person can learn how to control it.According to the Chinese understanding, this is the process of cultivating and directing Qi. It is when one uses the air flow to influence blood circulation and energy fluctuation, thus learning how to cure himself and preserve his health. It is for this mere reason thatin the Chinese culture it is considered that one's health depends on the way Qi flows in one's body.

\subsection{Wushu and Chinese Medicine}

Both Chinese medicine and Wushuare representative for the Chinese culture. They can be considered as an ancient science whose subject matter is the human body. Wushu and Chinese medicine share the same understanding that the human body is a complex system influenced by external factors and pay special attention 
to using Qi for both healing and improving one's health. Together with jing (精 body, essence) and shen (神 spirit) Qi (气 breath) builds the "three internal treasures". The fact that they are not reflected in the Western culture in the same way they are in the traditional Chinese worldview make them look as a secret practice. However, in Wushu they have their own concrete dimensions and can be experienced only through practice. In the Shaolin Quan the dragon stile develops the body, the snake style exercises Qi, the tiger style is for power, the leopard style is used for the bones and the crane style is beneficial for the spirit. These are different types of exercises which influence different functions of the human body and aim at improving one's health and developing better physical skills.

Since ancient times, Chinese people know that the human body consists of energy canals which are responsible for the air flow (Qi) and the blood circulation. There are places in the human body where these canals connect with each other or cross internal organs. Such places are known as acupuncture points, whose manipulation can influence the Qi flow positively or negatively. Both Wushu and Chinese medicine provide people with knowledge about how to do this. Knowing the effect of such manipulation on a person requires from a Wushu practitioner a high level of morality. For that reason, it is highlighted in the Shaolin guidebook about points manipulation that healing and protecting are the only reasons for learning this art [5].

\subsection{Wushu and Qi Gong}

Qi Gong is one of the Chinese traditional regimens. It is a system of breathing exercises that helps cultivating and directing Qi. It can be performed static or dynamic. The first known Qi Gong system is called Dao Yin and dates back to the Spring and Automn Period and the Warring States Period (770 - 221 BC). Later the Five Animals Qi Gong was developed by HuaTou (? - 208) during the Eastern Han Dynasty and in the course of time other systems appeared such as Ba Duan Jin and Yi Jin Jing[2]. Qi Gong exercises use the air flow to improvethe blood circulation and the way the energy fluctuates within the human body. They start from influencing the internal bodily environment, which eventually results in improving one's overall health condition. It is a harmonious process that helps a person to cure himself using his own Qi.

Wushu pays special attention to four types of skills one can develop: flexibility, light-footedness, physical qualities such as explosive or muscular power and inner skills which refer to Jing, Qi and Shen. That is why different Wushu schools have adopted different Qi Gong regimen and use them as a way to develop the inner skills one has. Furthermore, all the Wushu styles have high requirements for the way one breathes during practice. For example in Shaolin Quan, Tai JiQuan and XingyiQuan a practitioner needs to "drop Qi to the Dantian", i.e. a person should use abdomen when breathing in and out and opening and closing a motion should be in accordance to this process. InChinese tradition,Dantian is the center where one's vital energy accumulates to a higher level [6]. In modern science, two important things happen in this area: this is the place where fat caused by excess food consumption is being stored and later absorbed by the body. This is also where the embryo takes energy from. Therefore, abdominal breathing is crucial in Wushu.There are many motions in the Wushu routines where one's hand is placed near Dantian or it crosses it. The obvious reason behind this is that in a fighting situation, this is used to block the coming attack. The deeper meaning is that one's palms, especially the fingers, are considered the most sensitive parts of the human body. When these cross the Dantian area, energy flow is facilitated. There are different ways for Qi to be used depending on the characteristics of every stile. In Nan Quan, for example, which is characterised by its vigorous, athletic motions the breath and sound articulation are specially used for the accumulation of more power. Breathing with movement is a must and mastering the Qi Gong exercises can facilitate this process.

\subsection{Why Using Qi in Wushu's Practice is Beneficial for one's Health}

'The essence of Wushu is the attacking and defending nature of the movements' [7]. All the Wushu routines are a reflection of a fight. That is why many people think that Wushu's main purpose is the development of fighting skills. In fact, in the process of Wushu's practice more importance is attached to preserving and improving one's health. One the one hand, true martial arts skills can never be developed if one's health condition does not allow it. On the other hand, true martial arts skills are never developed for attacking people, but for self-defense. The human body is perfect by default. However, stress in daily lifeincreases day by day, which eventually leads to a negative influence on one's physical and mental health. The lack of physical activity contributes to this trend. This is one of the reasons why doing sports is a perfect way to release stress. Wushu does help people build strong muscles as well as gain more flexibility and even lose weight. On top of this, Wushu is unique in a way that it increases the awareness for the internal functions of the human body. Furthermore, it sharpens one's senses and develops an intuitive approach to knowledge. This is one of the differences that set Wushu and other Asian practices apart from Western sports. Learning how to cultivate and direct Qi in the Wushu's practice is considered to be more difficult than learning how to control the external motions of the body such as steps, kicks, spins etc. This is reflected in the saying "One who learns fist forms 
without practicing the basis exercise will attain nothing in his lifetime." Therefore, being in a good health is both a requirement for practicing Wushu and a result from the Wushu practice.

\section{What is Wude}

\section{Wushu and its Social Aspects}

Wushu can be seen as a sports phenomenon which has absorbed essential ideas of Chinese philosophy. It does not aim to harm people and develop fighting skills for the sake of fighting. It has the aspect of attack and defense in its routines but in its understanding about the social interactions a great deal of attention is put to the harmonious relations one should create and maintain with other people. Many people might say that Wushu is mainly practice of the body and does not need to deal with social relations. In fact, it is deeply rooted in Asian culture that teaching someone physical skills goes together with teaching someone social skills. In Yoga this is referred to as Yama and Niyama - guidelines for social interactions. They are considered the first steps one makes when starting the Yoga practice. Chinese culture being part of the Asian one and having influenced other Asian countries as well, highly values the harmony that should exist in all aspects of life. Wushu as a Chinese phenomenon has been strongly influenced by this understanding. That is why in Wushu there are high requirements not only for one's health condition, but for one's morality as well. According to an ancient Chinese saying if one wants to learn Wushu, he should first learn how to be a human. Buddhism calls for compassion for all living beings and non-violence, Daoism advocates living in a balance with nature and other people and Confucianism teaches us to kindheartedness. All these ideas have been adopted in Wushu's theory and contributed to the development of Wushu's martial virtue - Wude, where Wu (武) means military, martial and De (德) means virtue. Wude refers to one's actions, words, thoughts and social behavior. A Wushu practitioner should not cause any physical harm to others, he should pay attention of the way he uses words, for words can harm, too. Words and actions are expressions of the way one thinks. That is why a person should be aware of what he thinks and the way he interacts within society.

\section{Wulin and its Laws}

Wulin (武林) refers to all the Wushu practitioners regardless of which school they belong. From ancient times it has been clearly defined what is required from a person who wants to learn Wushu. Shaolin Shi JieYueare the guidelines for people from the Shaolin school. They need to show respect to the teacher, help other students from the same or any other school, being arrogant is not tolerated. Yong Chun Bai He Quan gives ten similar guidelines: a person should not start a fight out of selfishness or arrogance, out of desire to win, to have some kind of profit or be popular among people, wrongdoings, dishonesty, incitation of disharmony between people and playing around with them are strongly discouraged [5]. Fighting means inevitable cruelty. As we can see, Wushu provides people with offensive skills which can hurt the opponent, more importantly with defensive skills, but even more it provides them with the knowledge how to use these skills as a way for selfperfection. In the process of Wushu practice people are taught how to avoid the fight and how to treat others with respect. People practicing together should help each other, practicing in an atmosphere of understanding contributes to the understanding between all the people. A simple and yet clear expression of the idea about respecting people and not causing harm to them is the fist-clenching greeting that originates from the Confucian School. It has been adopted as an official greeting in Wushu competitions and demonstrations and that dates back from ancient times as a symbol of respect and good manners. Even now it is used from both teacher and students in the beginning and the end of a Wushu practice. It appears that practicing Wushu goes together with learning how to live in harmony with other people.

\section{Harmony between Human and Nature - Wushu as a Harmonious Path Harmony between Body and Mind}

According to the Chinese cosmology there is an original state of harmony between nature and human and one's highest goal is to maintain this state of balance. Everything that helps a person to reach and preserve this harmony is good and beneficial. The way Wushu is practiced is a reflection of this understanding, which is deeply rooted in all the aspects of Chinese culture. In order to be in harmony with nature, one should first reach a state of harmony between body and mind. Unlike Western culture which deals with 'body' and 'mind' as separate things, in the Chinese culture body and mind are clearly defined and the way they are to be synchronised is present in Wushu's practice. In the context of Wushu, the motions of the human body can be both internal and external. Internal refers to mind, heart and breathe, which together build the "three internal conformities", while external refers to eyes, hands and legs, which make the "three external conformities". It is a main requirement in all the different Wushu stiles, regardless the fact to which family they belong - NeiJia (internal styles) or WaiJia (external styles) that a person should use both body and mind, if he wants to keep the original harmonious balance with nature. There is another term as well, which is an exact reflection of this idea: YanShen. Yan refers to the eyes, part of the "external conformities", while Shen refers the spirit, which belongs to the internal ones. Many people consider that the external styles develop only physical abilities. In the Context of Chinese culture, however, body and mind are inseparable and all the Wushu styles have high requirements for using them as one while practicing. The different techniques 
can be seen as different interpretations of the same principle that they are one and represent a different approach towards the same goal - toharmonise them through practice. For that reason, Wushu is beneficial for both physical and psychological health.Being in harmony with oneself goes together with being in harmony with societywhich is reflected in the above mentioned concept of Wude.

\subsection{Harmony between Nature and Human}

From ancient times nature has been seen as a source of endless knowledge. Observing natural phenomena and analyzing the laws they follow inspired the Chinese people to create many useful exercises combining both body and mind so that one can improve one's health condition and mental stability. There are various techniques based on the imitation of animals - their hunting techniques, the ways of protection from other predators, breathing methods or even typical sounds they do when being in a dangerous situation. Shaolin Quan uses five animals, Xing Yi Quan has the techniques of twelve and TongbeiQuan has four in its routines.Often the way an exercise should be performed is compared to natural phenomena: body like a willow twig, as mighty as a lion, as powerful as a dragon stirring the sea, which shows the admiration for nature and the desire to act at one with it. According to the ancient believes human is part of nature and observing other people and their behavior can be useful as well. Therefore, the Drunkard style can be considered another interesting interpretation of a natural phenomenon. Furthermore, the techniques are relevant to the seasons, the climate and the day time and in Wushu's theory there are recommendations for the place, time and duration of practicing.

\subsection{The Concept of Yin and Yang}

The way a Wushu practitioner interacts with nature should follow natural laws for the human being is seen as part of nature. For example, Chinese people noticed that everything changes and everything has two aspects which are opposite to each other and at the same time, complement each other. This is first described in The Book of Changes and the dualistic system referred to as Yin - the passive, stable, quite, internal aspect, and Yang - the active, moving, external aspect. In the Wushu routines this can be a low stance followed by a high one, or a fast set of motions followed by a slow one, or one part of the body taking all the body weight, while the other is light and relaxed such as White Crane Spreads its Wings. Since Yin and Yang are opposite, this principle can refer to the speed, the intensity, the usage of the body parts etc., but it can also be applied in a fighting situation when attack and defense are constantly changing their positions. It can never be clearly defined when a defence will turn into an attack and when an attack does not actually aim in defending oneself. The battle field is a reflection of life - it is ever changing and the more closer is one to nature and acts in accordance with its laws, the more effective will be one's practice.

Life has drastically changed since those days back in the past. The way a person can harmoniously interact with nature and learn from it is reflected in all the Wushu stiles. Furthermore, Wushu gives concrete guidelines how to achieve harmony between body and mind. That is why Wushu can help people to turn back to nature and through devoted practice to feel the harmony ancient Chinese were looking for when developing the system of Wushu.

\section{Conclusion}

Concepts such as vital energy, balance between body and mind, as well as spiritual development might sound mysterious in the context of Western culture. Moreover, some philosophical aspects based on the idea of harmony with nature might be mistaken for religious practices. The unique about Wushu is that in its practice it embodies abstract ideas that in Western culture are only talked about. In the course of its development,Wushu has absorbed the wisdom of many people who have faced different challenges and overcome them in a different way. They all have contributed to Wushu's rich content and profound meaning by writing down their experience and guidelines for practical usage. For that reason, Wushu can be seen as a system of practical guidelines and a reflection of ancient wisdom. Furthermore, it can be used as a bridge between the Western and Eastern cultures which can contribute for the better understanding of the Chinese traditional worldview.

\section{References}

[1] Wu Bin, Essentials of Chinese Wushu (Beijing: Foreign Language Press, 1992), 149.

[2] Yu Gongbao, Wushu Exercise for Life Enhancement (Beijing: Foreign Language Press, 1991), 3.

[3] Holt, Ronald, Ki/QI, in Martial Arts of the World, ed. Thomas A Green, (Santa Barbara, California: ABC-CLIO, 2001), 260--62.

[4] Powers, Scott K., and Howley, Edward T. Exercise Physiology: Theory and Application to Fitness and Performance. 4th ed. New York: McGrow Hill, 2001.

[5] Research Committee of the National Sports Colleges and Universities, Wushulilunjichu [Basic Theory of Wushu] (Beijing, China: RenminTiyuChubianshi, 1997.)

[6] Yang, Jwing-Ming."Embryonic Breathing for Martial Arts.” Fighting Arts.com., accessed April 17, 2013. http://www.fightingarts.com/reading/article.php?id=571/.

[7] Meng, Tao. Learn and Practice Wushu (Beijing: Beijing Sports University Press, 2010), 9. 